\title{
Nonstationary modeling of extreme precipitation in China
}

\author{
Meng Gao ${ }^{\mathrm{a}, *}$, Dingyuan Mo ${ }^{\mathrm{a}, \mathrm{b}}$, Xiaoqing $\mathrm{Wu}^{\mathrm{a}}$ \\ a Key Laboratory of Coastal Environmental Processes and Ecological Remediation, Yantai Institute of Coastal Zone Research, CAS, Yantai 264003, China \\ b University of Chinese Academy of Sciences, Beijing 100049, China
}

\section{A R T I C L E I N F O}

\section{Article history:}

Received 18 March 2016

Received in revised form 10 July 2016

Accepted 13 July 2016

Available online 15 July 2016

\section{Keywords:}

Precipitation extreme

Stationarity

Trend

GEV distribution

Return level

\begin{abstract}
A B S T R A C T
The statistical methods based on extreme value theory have been traditionally used in meteorology and hydrology for a long time. Due to climate change and variability, the hypothesis of stationarity in meteorological or hydrological time series was usually not satisfied. In this paper, a nonstationary extreme value analysis was conducted for annual maximum daily precipitation (AMP) at 631 meteorological stations over China for the period 1951-2013. Stationarity of all 631 AMP time series was firstly tested using KPSS test method, and only 48 AMP time series showed non-stationarity at $5 \%$ significance level. The trends of these 48 nonstationary AMP time series were further tested using M-K test method. There were 25 nonstationary AMP time series mainly distributed in southern and western China showing significant positive trend at $5 \%$ level. Another 5 nonstationary AMP time series with significant negative trends were near northern urban agglomeration, Sichuan Basin, and central China. For these nonstationary AMP time series with significant positive or negative trends, the location parameter in generalized extreme value (GEV) distribution was assumed to be time-varying, and the trends were successfully characterized by the nonstationary GEV models. For the remaining 18 nonstationary AMP time series mainly in the eastern portion of China, no significant trend was detected. The correlation analysis showed that only 5 nonstationary AMP time series were significantly correlated with one or two of the four climate indices EASMI, WPI, SOI, and PDO. Then, the location and scale parameters in the GEV distribution were modeled as functions of the significantly correlated climate indices. The modeling results in this study showed that the nonstationary GEV distributions performed better than their stationary equivalents. Finally, 20-year and 50-year return levels of precipitation extremes at all 631 stations were estimated using the best fitting distribution for the year 1961 and 2013 , respectively.
\end{abstract}

(c) 2016 Elsevier B.V. All rights reserved.

\section{Introduction}

Extreme value theory (EVT), one of the important branches of statistics, has been widely used in meteorology and hydrology for a long time (Katz et al., 2002; Soukissian and Tsalis, 2015). Climate or hydrology extremes could be successfully characterized by the probability distributions derived from EVT (Feng et al., 2007; Li et al., 2013). For the most part, EVT applied in meteorology and hydrology assumes that these extreme events are stationary (Katz et al., 2002). However, the stationarity assumption has been gradually challenged due to climate change and variability or human intervention (Salas and Obeysekera, 2014). Then, climatic and hydrological extremes exhibit some type of non-stationarity in the form of trends, shifts or a combination of them (Olsen et al., 1999; Kiem et al., 2003; Villarini et al., 2009). Nonstationarity may affect both the severity and frequency of these extreme events (Olsen et al., 1998; Wigley, 2009; Mika, 2013; Radinović and

\footnotetext{
* Corresponding author.

E-mail address: mgao@yic.ac.cn (M. Gao).
}

Ćurić, 2014; Monier and Gao, 2015); therefore, it is suggested that nonstationary probability distribution models need to be identified and possibly used for risk management and engineering design (Katz, 2013; Cheng et al., 2014; Salas and Obeysekera, 2014).

In this paper, we apply nonstationary modeling technique to study the precipitation extremes over China for the period 1951-2013. Precipitation is very crucial to our planet, because it is a major component of the water cycle by depositing most of the fresh water (Radinovic and Ćurić, 2009). However, extreme precipitation events also cause floods resulting in great loss of lives and properties, especially in extreme seasons (Radinović and Ćurić, 2013, 2014). China also suffers from floods caused by precipitation extremes (Zhai et al., 2005); therefore, it is worthy to assess the adverse influences of extreme precipitation events. In recent literatures, changes in trend and frequency have been detected in precipitation extremes in China (Zhai et al., 2005; Su et al., 2006; Qian and Qin, 2008; Xu et al., 2011; You et al., 2011). The non-stationarity in the extreme precipitation time series was also successfully modeled with generalized extreme value (GEV) and generalized Pareto distribution (GPD) by introducing inconstant parameters (Fischer et al., 2012a, 2012b; Feng et al., 2007; Du et al., 2014). These previous studies primarily focused attention on the long term trends of 
precipitation extremes and its correlation with climate change, but non-stationarity in precipitation extremes related to climate change and variability has not been extensively studied.

China is located in East Asia; therefore, the climate is strongly influenced by the important subsystem of Asian monsoon, East Asian monsoon (Ding and Chan, 2005; Zhou et al., 2008). Specifically, it was found that East Asian summer monsoon determined the spatiotemporal variability of summer rainfall over China (Ding and Chan, 2005; Zhao and Zhou, 2009). The Western Pacific subtropical high is also an important weather and climate system in the Asian monsoon region that contributes largely to the complexity and variability of the China's rainfall distribution and precipitation anomalies in summer (Sui et al., 2007; Zhang et al., 2015). The Asian monsoon system is also strongly affected by El Niño Southern Oscillation (ENSO) that has the greatest impact on the year-to-year variability of the global climate (Tanaka, 1997; Wang et al., 2000). Moreover, some low-frequency climate variability such as Pacific Decadal Oscillation (PDO) also influences global precipitation anomalies on decadal timescale (Kiem et al., 2003; Villafuerte et al., 2014). To represent the dependence of meteorological time series on climatic forcing, nonstationary extreme value distribution model taking climate indices as covariates have been applied (Villarini et al., 2010). In this study, we also use nonstationary GEV distribution with time and climate indices as the potential covariates to model the nonstationary precipitation extremes in China.

\section{Data}

The daily precipitation dataset (1951-2013) that was provided by the National Meteorological Information Center (NMIC) of China Meteorological Administration (CMA) was used to extract extreme precipitation time series. The data quality was also controlled by the NMIC (Qian and Lin, 2005). There are 631 meteorological stations having the good quality and continuous daily records longer than 50 years (Fig. 1). In this study, extreme precipitation is defined as the maximum daily precipitation, and then the annual maximum daily precipitation (AMP) time series at all 631 stations could be simply computed using the daily precipitation dataset. Each station was labeled by a unique ID coded using 6-digit number.

The East Asian summer monsoon index (EASMI, Fig. 2) is defined as an area-averaged seasonally (JJA) dynamical normalized seasonality (DNS) at $850 \mathrm{hPa}$ within the East Asian monsoon domain $\left(10^{\circ}-40^{\circ} \mathrm{N}\right.$, $110^{\circ}-140^{\circ} \mathrm{E}$ ) (Li and Zeng, 2003, 2005). The annual EASMI time series was collected by Dr. Li J.P. and can be directly downloaded from the following website (http://ljp.gcess.cn/dct/page/65577).

The Western Pacific subtropical high is quantified by WP index (WPI, Fig. 2) that signifies the zonal and meridional variation of the

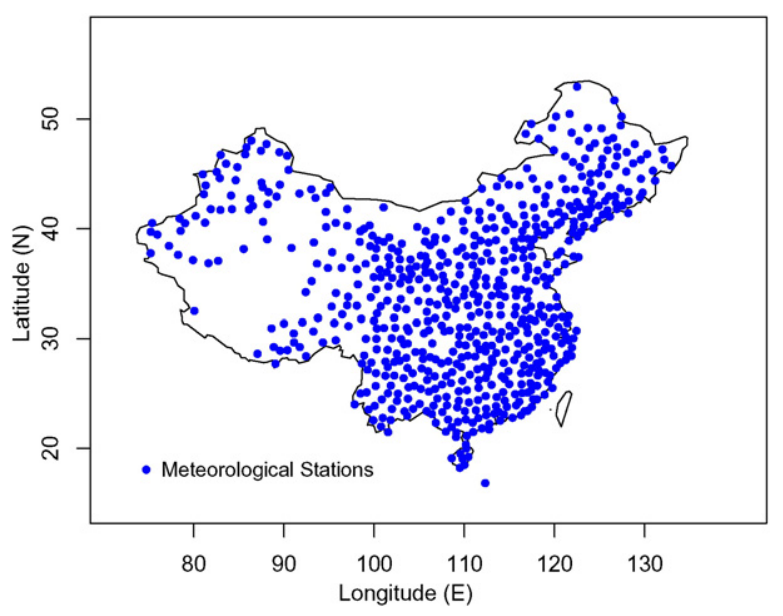

Fig. 1. Geographical distribution of the 631 meteorological stations in China. location and intensity of the East Asian jet stream entrance region (Barnston and Livezey, 1987). The WPI data (monthly/annual) was provided by the U.S. National Centers for Environmental Prediction (NCEP, http://www.cpc.ncep.noaa.gov/data/).

ENSO is generally at its peak during November-January (Trenberth, 1997), and its effect on extreme precipitation is in the following summer (Lin and Lu, 2009). In this study, the Southern Oscillation Index (SOI, Fig. 2), which is a standardized difference between the two barometric pressures between observation stations at Darwin, Australia and Tahiti, is used to quantify ENSO. We computed the average of monthly SOI from November to next January to generate the SOI series from 1950 to 2012 . The monthly SOI index could be directly downloaded from national center for environmental information, NOAA (http://www.ncdc.noaa.gov/).

PDO index (Fig. 2) is the standardized principal component time series, and the monthly time series of PDO index since 1900 can be obtained from the following website http://research.jisao.washington.edu/ pdo/PDO.latest. In this study, the annual PDO index was based on the average November-March leading principal component of monthly SST anomalies poleward of $20^{\circ} \mathrm{N}$ in the Pacific Ocean (Mantua and Hare, 2002).

\section{Methodology}

Stationarity and trend of the AMP time series will be firstly tested. Only nonstationary AMP time series are modeled by nonstationary GEV distribution. For nonstationary AMP time series with significant trends, time will be chosen as covariate in location parameter of GEV distribution. Otherwise, significant correlated climate indices are used as covariates in both location and scale parameter in GEV distribution, respectively. With the best fitting GEV distribution model, return levels are also estimated.

\subsection{Test methods}

The stationarity test is carried out using KPSS test method (Kwiatkowski et al., 1992). The objective time series is assumed to be the sum of deterministic trend, random walk, and stationary error with the following linear regression model

$x_{t}=r_{t}+\beta_{t}+\varepsilon_{t}$

where $r_{t}$ is a random walk, $\beta_{t}$ is a deterministic trend, and $\varepsilon_{t}$ is a stationary error. Here, $r_{t}=r_{t-1}+u_{t}$, and $u_{t}$ is independent and identical distributed $N\left(0, \sigma_{u}^{2}\right)$. If the time series is stationary around a deterministic trend, the null hypothesis is $\sigma_{u}^{2}=0$, while the alternative hypothesis is $\sigma_{u}^{2}>0$. In another case, if the time series is stationary around a fixed level, the null hypothesis will be $\beta_{t}=0$. In this study, the stationarity test will be implemented using package "tseries" in R environment (R Development Core Team, 2014).

The Mann-Kendall (M-K) test method is applied for detecting monotonic trends in the AMP time series. The M-K test is a rank-based nonparametric trend detection method that is less sensitive to outliers than parametric statistics, such as Pearson's correlation coefficient (Kendall, 1938; Mann, 1945). The null hypothesis in M-K test states that there is no trend in the time series and observations are randomly ordered. On the contrary, the alternative hypothesis means that there are increasing or decreasing monotonic trends. In this study, the detection of trend will be completed using the package "Kendall" in $\mathrm{R}$ environment.

The statistical dependence of AMP time series on climate indices (EASMI, WPI, SOI, and PDO) is tested using Spearman's correlation test method. Assuming there are two time series of $X_{t}$ and $Y_{t}$ of size $n, x_{i}$ and $y_{i}$ are the corresponding ranks, then the difference between ranks 
is computed as $d_{i}=x_{i}-y_{i}$. Then, the rank correlation coefficient $\rho$ is computed as

$\rho=1-\frac{6 \sum d_{i}^{2}}{n\left(n^{2}-1\right)}$

A positive $\rho$ corresponds to an increasing monotonic trend between $X$ and $Y$, while a negative $\rho$ corresponds to a decreasing monotonic trend. In this study, Spearman's correlation test is completed using package "stats" in R environment.

\subsection{Nonstationary GEV model}

According to EVT, the probability distribution of extremes extracted from a time series asymptotically approaches the generalized extreme value (GEV) distribution as the number of samples becomes large (Jenkinson, 1955). The probability distribution function of the GEV distribution is given by:

$$
F(x ; \mu, \sigma, \xi)=\exp \left\{-\exp \left[-\left(1+\xi \frac{x-\mu}{\sigma}\right)\right]\right\}, \quad 1+\frac{\xi(x-\mu)}{\sigma}>0
$$

where $\mu, \sigma$ and $\xi$ are the location, scale, and shape parameters, respectively. Constant parameters correspond to stationary GEV distribution model.

Non-stationarity is introduced by expressing one or more of the parameters of the GEV distribution as a function of time, or climate indices. For nonstationary AMP time series with significant trend, the location parameter follows a linear model of the year: $\mu=\mu_{0}+\mu_{1} * y_{t}$. For nonstationary AMP time series with nonsignificant trend, climate index that is significantly correlated with AMP time series will be used as covariates. Here, for simplicity the shape parameter $\xi$ is supposed to be constant, and the location parameter and shaper parameter is assumed to be linearly dependent on one or more climate indices:

$\mu=\mu_{0}+\mu_{1} y_{1}+\mu_{2} y_{2}+\ldots$

$\sigma=\sigma_{0}+\sigma_{1} y_{1}+\sigma_{2} y_{2}+\ldots$

where $y_{i}$ is the $i$-th climate index. $\mu_{i}$ and $\sigma_{i}$ are the coefficients of the linear models needed to be estimated. Maximum likelihood method is used for parameter estimation in both stationary and nonstationary GEV distributions.

For the purpose of comparison, stationary GEV distribution that is referred to as $M 0$. Nonstationary GEV distribution with time or one climate index as covariate in location parameter will be referred as $M 1$. The goodness of fit of two models $M 0$ and $M 1$ will be compared using likelihood ratio test (Coles, 2001) since $M 0$ can be treated as a special case of $M 1$. Akaike information criterion (AIC) is also computed for model fitting evaluation (Akaike, 1974). For nonstationary AMP time series without significant trend, a variety of nonstationary GEV distribution models can be derived from Eqs. (4) and (5). If the focal AMP time series is significantly correlated with one (or two) climate index, three (or fifteen) nonstationary GEV distribution models will be fitted. If the focal AMP time series is significantly correlated with more than two climate indices, only two climate indices with larger absolute correlation

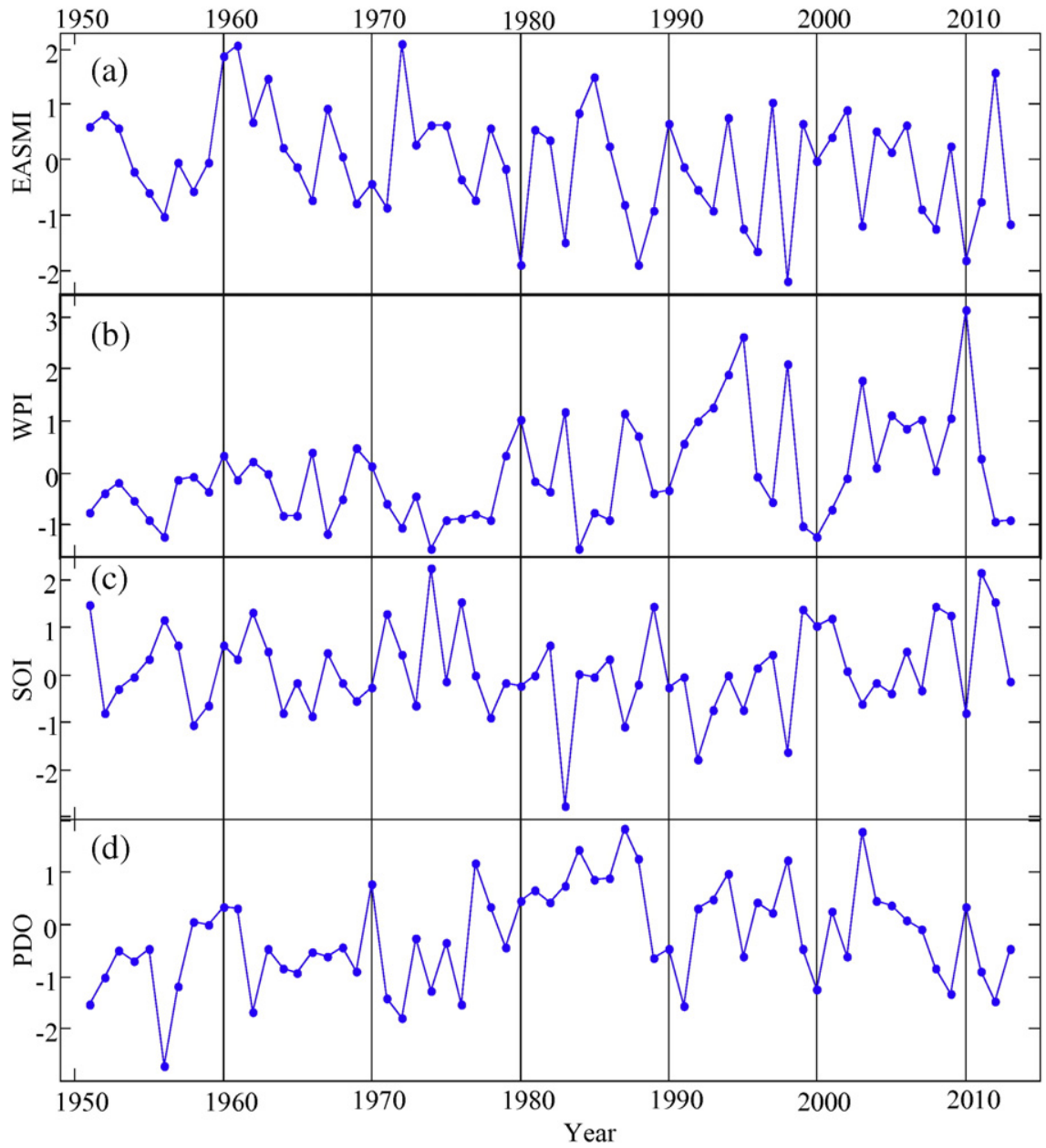

Fig. 2. Time series of four climate indices: EASMI, WPI, SOI, and PDO. 
coefficients are reserved. Out of these stationary and nonstationary models, the best fitting one is also selected according to AIC. Graphical diagnostics are also explored for evaluating the quality of the model fitting. Specifically, P-P plot is used, where a perfect fit is indicated if all scatters follow the 1:1 line. For each AMP time series, once the best fitting model has been identified, it is easy to compute the $T$-year return level of precipitation extremes by substituting the maximum likelihood estimates of three model parameters. The T-year return level denoted using $x_{T}(t)$, either constant or varying, can be computed as:

$x_{T}(t)=\hat{\mu}-\frac{\hat{\sigma}}{\hat{\xi}}\left\{1-\left[-\log \left(1-\frac{1}{T}\right)\right]^{-\hat{\xi}}\right\}$

20-year and 50-year return levels of precipitation extremes for the year 1961 and 2013 will be predicted using Eq. (6) derived from the corresponding GEV distribution.

\section{Results}

The stationarity test results showed that 563 AMP time series were considered to be stationary at a 5\% significance level. For the other 48 AMP time series, the null hypothesis 'level' or 'trend' stationarity was rejected by KPSS test at the $5 \%$ level. The geographic locations of the 48 meteorological stations were presented in Fig. 3. It seemed that these 48 stations were not clustered distributed but almost randomly distributed over China. Next, the trends of the 48 nonstationary AMP time series were tested using M-K test method, and the test results were also displayed in Fig. 3. There were 25 nonstationary AMP time series showing significant ( $5 \%$ level) positive trends, and 5 nonstationary AMP time series showing significant (also 5\% level) negative trends. No significant trend was detected for the other 18 nonstationary AMP time series. From Fig. 3, we found that AMP time series with significant
Table 1

The modeling results for the 30 nonstationary AMP time series with significant trends.

\begin{tabular}{|c|c|c|c|c|c|c|}
\hline \multirow[b]{2}{*}{ Class } & \multirow[b]{2}{*}{$\begin{array}{l}\text { Station } \\
\text { ID }\end{array}$} & \multirow[b]{2}{*}{$\begin{array}{l}\text { Lat } \\
\text { (N) }\end{array}$} & \multirow[b]{2}{*}{ Lon (E) } & \multicolumn{2}{|l|}{ AICa } & \multirow[b]{2}{*}{$p$-Value $\S$} \\
\hline & & & & $\begin{array}{l}\text { Model } \\
0\end{array}$ & $\begin{array}{l}\text { Model } \\
1\end{array}$ & \\
\hline \multirow{25}{*}{$\begin{array}{l}\text { Non-stationary, } \\
\text { significant positive } \\
\text { trend }\end{array}$} & 51,087 & $46^{\circ} 59^{\prime}$ & $89^{\circ} 31^{\prime}$ & 410.006 & 400.791 & 0.001 \\
\hline & 51,186 & $46^{\circ} 40^{\prime}$ & $90^{\circ} 23^{\prime}$ & 393.726 & 379.763 & 0.000 \\
\hline & 51,241 & $45^{\circ} 56^{\prime}$ & $83^{\circ} 36^{\prime}$ & 397.000 & 395.007 & 0.046 \\
\hline & 51,431 & $43^{\circ} 57^{\prime}$ & $81^{\circ} 20^{\prime}$ & 422.595 & 420.917 & 0.055 \\
\hline & 51,720 & $40^{\circ} 30^{\prime}$ & $79^{\circ} 3^{\prime}$ & 404.740 & 399.467 & 0.007 \\
\hline & 51,777 & $39^{\circ} 2^{\prime}$ & $88^{\circ} 10^{\prime}$ & 407.340 & 406.256 & 0.079 \\
\hline & 52,101 & $43^{\circ} 36^{\prime}$ & $93^{\circ} 3^{\prime}$ & 425.391 & 420.420 & 0.008 \\
\hline & 52,112 & $43^{\circ} 46^{\prime}$ & $95^{\circ} 8^{\prime}$ & 304.905 & 303.767 & 0.076 \\
\hline & 52,495 & $40^{\circ} 10^{\prime}$ & $104^{\circ} 48^{\prime}$ & 425.274 & 423.172 & 0.043 \\
\hline & 52,576 & $39^{\circ} 13^{\prime}$ & $101^{\circ} 41^{\prime}$ & 400.729 & 384.824 & 0.000 \\
\hline & 52,737 & $37^{\circ} 22^{\prime}$ & $97^{\circ} 22^{\prime}$ & 411.851 & 399.214 & 0.000 \\
\hline & 52,825 & $36^{\circ} 26^{\prime}$ & $96^{\circ} 25^{\prime}$ & 336.056 & 337.868 & 0.665 \\
\hline & 52,836 & $36^{\circ} 18^{\prime}$ & $98^{\circ} 6^{\prime}$ & 392.744 & 390.317 & 0.035 \\
\hline & 55,279 & $31^{\circ} 23^{\prime}$ & $90^{\circ} 1^{\prime}$ & 375.764 & 369.823 & 0.005 \\
\hline & 55,472 & $30^{\circ} 57^{\prime}$ & $88^{\circ} 38^{\prime}$ & 338.596 & 327.514 & 0.000 \\
\hline & 55,664 & $28^{\circ} 38^{\prime}$ & $87^{\circ} 5^{\prime}$ & 408.523 & 404.140 & 0.012 \\
\hline & 56,459 & $27^{\circ} 56^{\prime}$ & $101^{\circ} 16^{\prime}$ & 411.772 & 407.557 & 0.013 \\
\hline & 57,237 & $32^{\circ} 4^{\prime}$ & $108^{\circ} 2^{\prime}$ & 634.187 & 630.385 & 0.016 \\
\hline & 57,405 & $30^{\circ} 30^{\prime}$ & $105^{\circ} 33^{\prime}$ & 636.960 & 637.981 & 0.323 \\
\hline & 57,993 & $25^{\circ} 52^{\prime}$ & $115^{\circ} 0^{\prime}$ & 574.037 & 571.560 & 0.034 \\
\hline & 58,531 & $29^{\circ} 43^{\prime}$ & $118^{\circ} 17^{\prime}$ & 611.368 & 606.906 & 0.011 \\
\hline & 59,134 & $24^{\circ} 29^{\prime}$ & $118^{\circ} 4^{\prime}$ & 668.842 & 662.234 & 0.003 \\
\hline & 59,218 & $23^{\circ} 8^{\prime}$ & $106^{\circ} 25^{\prime}$ & 560.815 & 558.501 & 0.038 \\
\hline & 59,855 & $19^{\circ} 14^{\prime}$ & $110^{\circ} 28^{\prime}$ & 712.904 & 701.144 & 0.000 \\
\hline & 59,948 & $18^{\circ} 14^{\prime}$ & $109^{\circ} 31^{\prime}$ & 621.550 & 614.316 & 0.002 \\
\hline \multirow{5}{*}{$\begin{array}{l}\text { Non-stationary, } \\
\text { significant negative } \\
\text { trend }\end{array}$} & 53,959 & $35^{\circ} 3^{\prime}$ & $111^{\circ} 3^{\prime}$ & 514.790 & 514.282 & 0.113 \\
\hline & 54,429 & $40^{\circ} 12^{\prime}$ & $117^{\circ} 57^{\prime}$ & 610.525 & 608.439 & 0.043 \\
\hline & 54,511 & $39^{\circ} 48^{\prime}$ & $116^{\circ} 28^{\prime}$ & 613.470 & 609.271 & 0.013 \\
\hline & 56,492 & $28^{\circ} 48^{\prime}$ & $104^{\circ} 36^{\prime}$ & 628.929 & 626.319 & 0.032 \\
\hline & 57,051 & $34^{\circ} 48^{\prime}$ & $111^{\circ} 12^{\prime}$ & 509.027 & 507.383 & 0.056 \\
\hline
\end{tabular}

a Model 0: stationary GEV distribution; Model 1: nonstationary GEV distribution with time as the only covariate in location parameter.

$\S$ Likelihood ratio test; $p$-value in bold indicate significance at 5\% level.

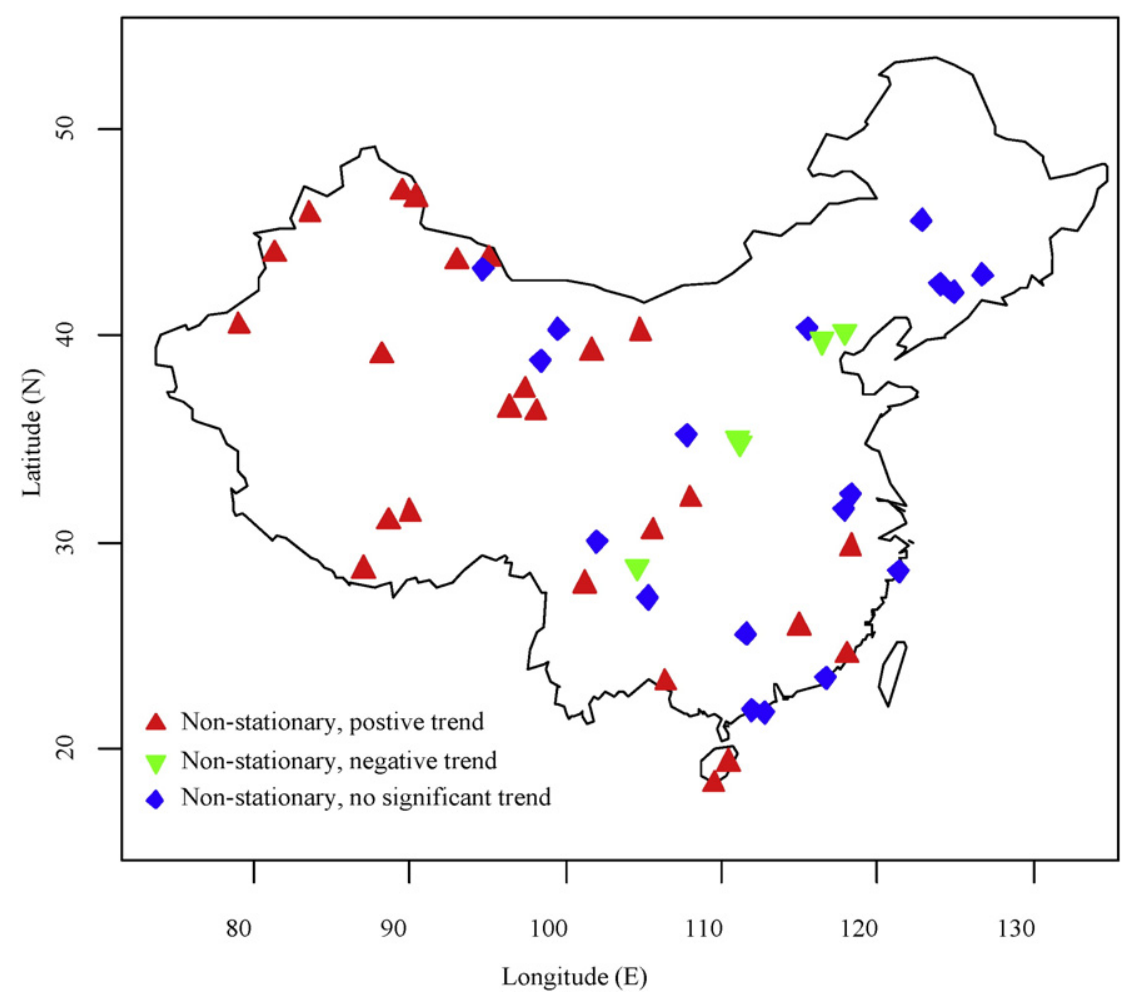

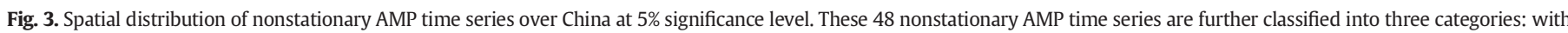
positive trends, with negative trend, and without significant trends $5 \%$ level. 
positive trends were mainly distributed in the southern and western China. The nonstationary AMP time series without significant trends were mainly located in eastern China.

The modeling results for the 30 nonstationary AMP time series with significant positive or negative trends were summarized in Table 1. A smaller AIC indicated a better fitting, and a $p$-value of likelihood test $<0.05$ mean that the two models were significantly different at $5 \%$ level. From Table 1, it could be seen that for most stations M1 with time as the covariate performed better than MO according to AIC and likelihood ratio test. Fig. 4 showed the observed values of AMP, the estimated median, and the 5th and 95th percentiles at 6 representative stations (four with positive trends and 2 with negative trends). It was worthy to note that although the nonstationary GEV model did not perform better than the stationary one in fitting AMP time series at station
57,405 (Fig. 4c), the trend in AMP was still successfully captured by the nonstationary GEV distribution model.

The correlations between nonstationary AMP time series without significant trends and the four climate indices (EASMI, WPI, SOI, and PDO) were shown in Fig. 5. At 5\% significance level, there was no AMP time series correlates with WPI time series. Two AMP time series at station 52,218 and 53,929 only correlated with SOI time series at 5\% significance level. One AMP time series at station 58,236 (or 54,405) was significantly correlated with EASMI (or PDO), respectively. For the above four stations, one stationary and three nonstationary GEV distributions with the correlated climate indictor as covariate were used to fit the nonstationary AMP time series, respectively. Table 2 summarized the fitting results, and Fig. 6 showed the observed values of AMP time series, the estimated median, and the 5th and 95th percentiles of the
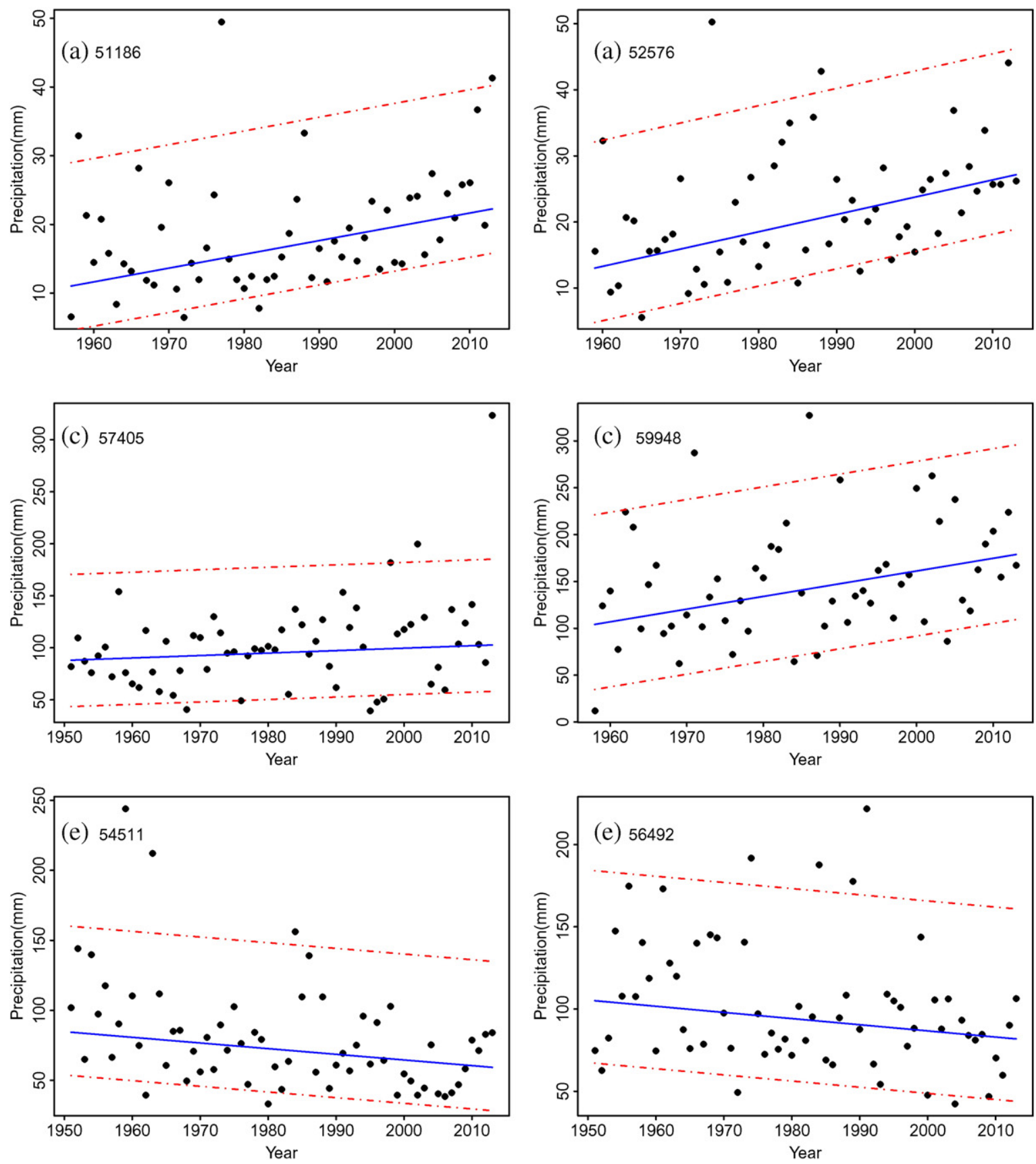

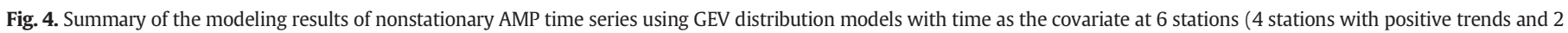
stations with negative trends). The results show the observed values of AMP (dots), the estimates of the median (solid lines), and the 5th and 95th percentiles (dashed lines). 

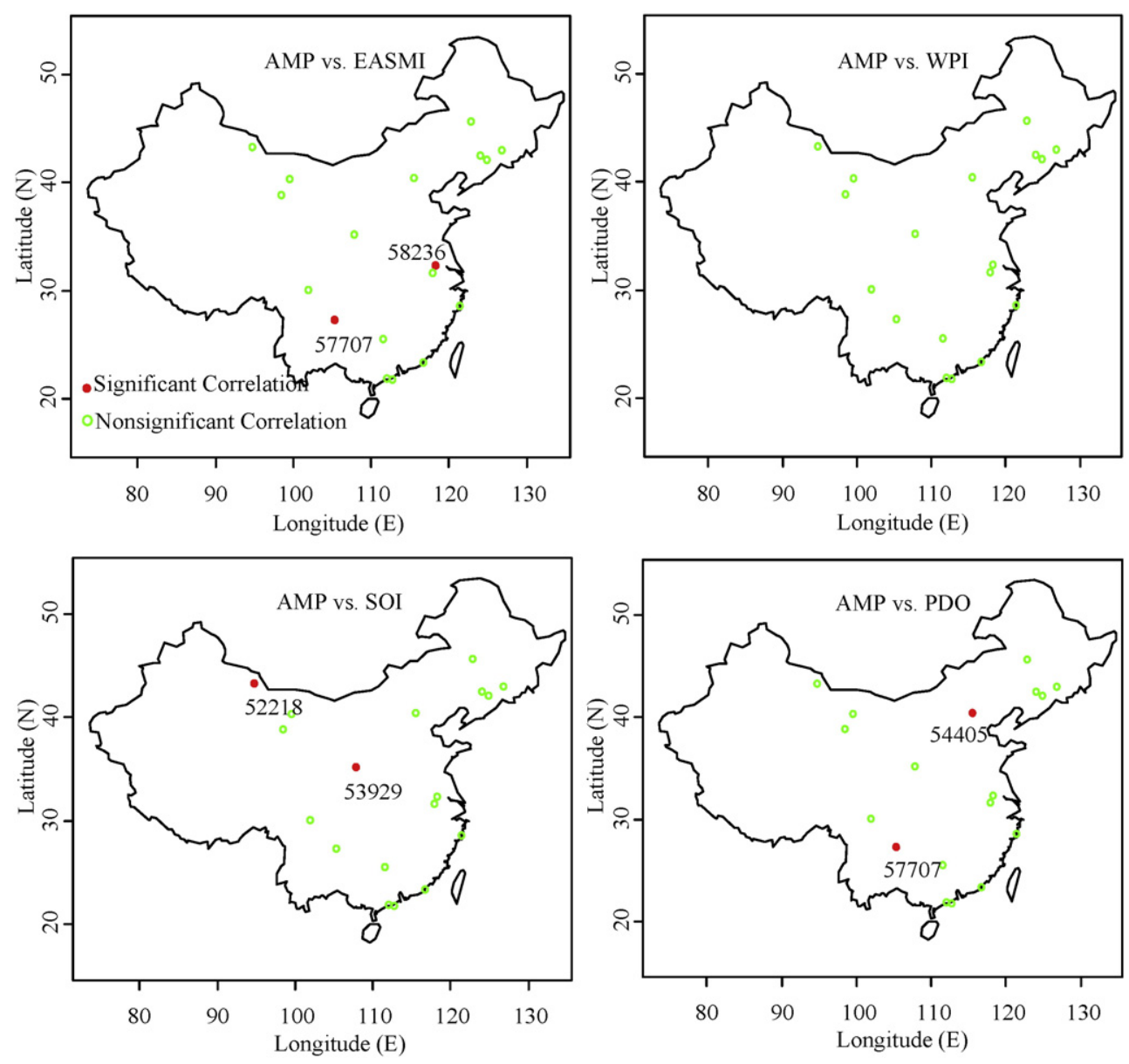

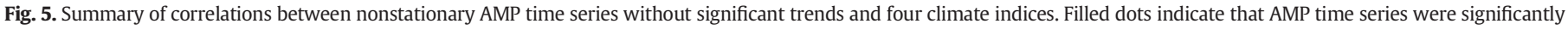
correlated with the climate index at $5 \%$ level, while the other circles indicate nonsignificant correlations.

best fitting model. Here, MO also denoted the stationary GEV distribution model, while $M 1$ and $M 2$ were nonstationary GEV distribution model with the solely correlated climate index as covariate in parameter $\mu$ and $\sigma$, respectively. In $M 3$, both $\mu$ and $\sigma$ were linearly dependent on the climate index. For AMP time series at station 52,118, the stationary model $M 0$ was the best one. Model M2 with EASMI as covariate performed best, when AMP time series at station 58,236 was fitted. For AMP time series at station 53,929 and 54,405, model $M 1$ with SOI or PDO as covariate in location parameter gave the best fitting according to AIC.

The last nonstationary AMP time series at station 57,707 was found to be significantly correlated with both EASMI and PDO at 5\% level (Fig. 5). We applied one stationary and fifteen nonstationary GEV distribution models to fit the AMP time series at station 57,707. The fitting performance was also evaluated according to AIC. The four best performing

Table 2

The modeling results for the 4 nonstationary AMP time series without significant trends.

\begin{tabular}{lllllllll}
\hline \multirow{2}{*}{ Covariatea } & Station ID & Lat (N) & Lon (E) & \multicolumn{2}{l}{ AICb } & & & \\
\cline { 5 - 8 } & & & & & Model 0 & Model 1 & Model 2 & Model 3 \\
\hline \multirow{2}{*}{ EASMI } & 58,236 & $32^{\circ} 18^{\prime}$ & $118^{\circ} 18^{\prime}$ & 637.45 & 638.36 & $\mathbf{6 3 6 . 0 3}$ & 636.35 \\
SOI & 52,118 & $43^{\circ} 16^{\prime}$ & $94^{\circ} 42^{\prime}$ & $\mathbf{3 9 6 . 4 2}$ & 397.26 & 397.69 & 397.04 \\
& 53,929 & $35^{\circ} 12^{\prime}$ & $107^{\circ} 48^{\prime}$ & 517.13 & $\mathbf{5 1 6 . 6 9}$ & 519.13 & 518.63 \\
PDO & 54,405 & $40^{\circ} 24^{\prime}$ & $115^{\circ} 30^{\prime}$ & 499.01 & $\mathbf{4 9 7 . 6 6}$ & 500.26 & 498.39 \\
\hline
\end{tabular}

\footnotetext{
a For the specific station, only the climate index is significantly correlated with the AMP time series is used as covariate in nonstationary modeling.

b Model 0: stationary GEV distribution; M1-M3: nonstationary GEV distribution with climate index as covariate in location parameter, scale parameter, or both location and scale parameter simultaneously. AIC values in bold indicate the best fitting model.
}

GEV distribution models were M14 $(\mu \sim$ PDO, $\sigma \sim$ EASMI + PDO, AIC $=$ 545.65), $M 10(\sigma \sim$ EASMI + PDO, AIC $=552.12), M 4(\sigma \sim \mathrm{PDO}, \mathrm{AIC}=$ $552.94)$, and $M 2(\sigma \sim$ EASMI, AIC $=556.43)$. Fig. 7 showed the P-P plot of the above four nonstationary GEV distribution models and that of the stationary one with AIC $=562.85$. The observed values of AMP, the estimated median, and the 5th and 95th percentiles based on model M14 were shown in Fig. 7. According to the diagnostics plots and AIC, the selected model M14 performed reasonably well.

Finally, the best fitting models were used to estimate the 20-year and 50-year return levels of precipitation extremes at all 631 station for the year 1961 and 2013, respectively. For the stationary AMP time series, stationary GEV distribution was considered as the best fitting model. Nonstationary AMP time series those had no significant trends and did not correlate with any climate indictor significantly were also fitted using stationary GEV distribution model. Fig. 8 showed the spatial distribution of the 20-year and 50-year return levels of precipitation extremes over China in 1961 and 2013, respectively. As nonstationary AMP time series with significant trends were mainly distributed in western China and meteorological stations there were sparse, the difference between return level in 1961 and that in 2013 was not very obvious except in the western China.

\section{Discussion}

IPCC's fourth assessment report predicted that both frequency and intensity of extreme precipitation events would increase worldwide (IPCC, 2007). At national or regional scale, the changes of precipitation extremes were also extensively studied, and significant trends in precipitation extremes were detected in the United States, Australia, 

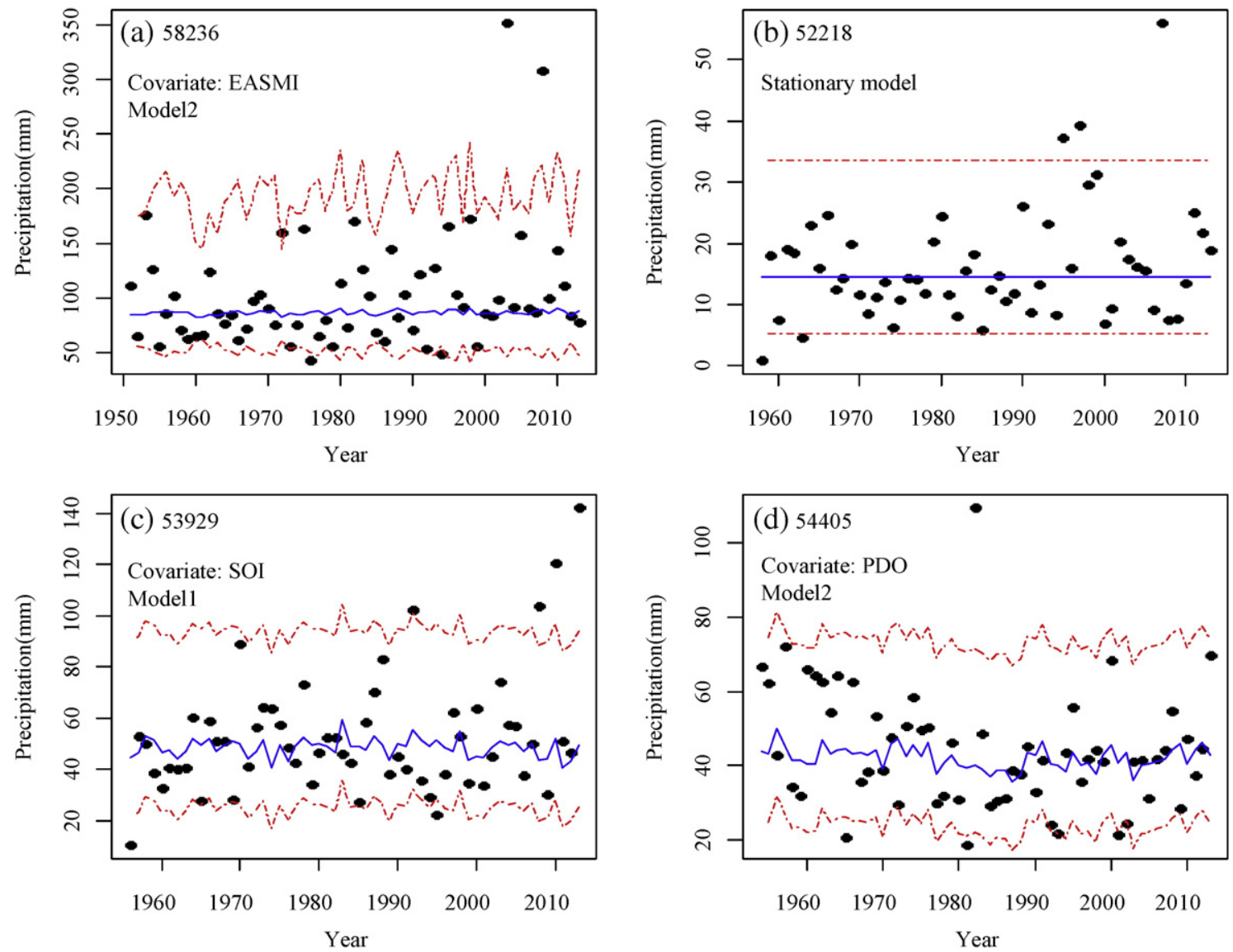

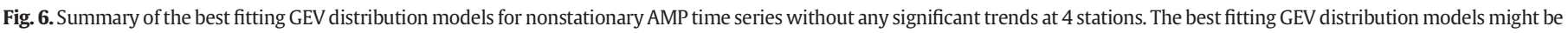

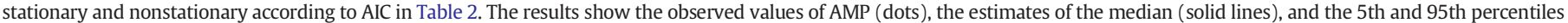
(dashed lines).

Europe, South and Southeast Asia (Klein Tank and Können, 2003; Goswami et al., 2006; Fu et al., 2010; Boccolari and Malmusi, 2013; Cino et al., 2014; Limsakul and Singhruck, 2016; Singh and Goyal, 2016). In China, significant trends in precipitation extremes have also been detected with apparent regional differences (Zhai et al., 2005; Qian and Qin, 2008; Xu et al., 2011; You et al., 2011; Deng et al., 2014; Song et al., 2015; Sun et al., 2016). Under the background of climate change, it is worthy to study precipitation extreme and assess its adverse influence, because extreme precipitation events are considered as the major causes of severe floods in China (Zhai et al., 2005). In this study, not only the trends of precipitation extremes were detected but also the stationarity of AMP time series were examined. Nonstationary extreme value analysis was applied to the precipitation extremes at 631 weather stations over China.

Firstly, nonstationary AMP time series with significant positive trends at $5 \%$ level were detected at 25 weather stations, which were mainly distributed in the southern and western China. This finding is consistent with the distribution of stations with positive trends in
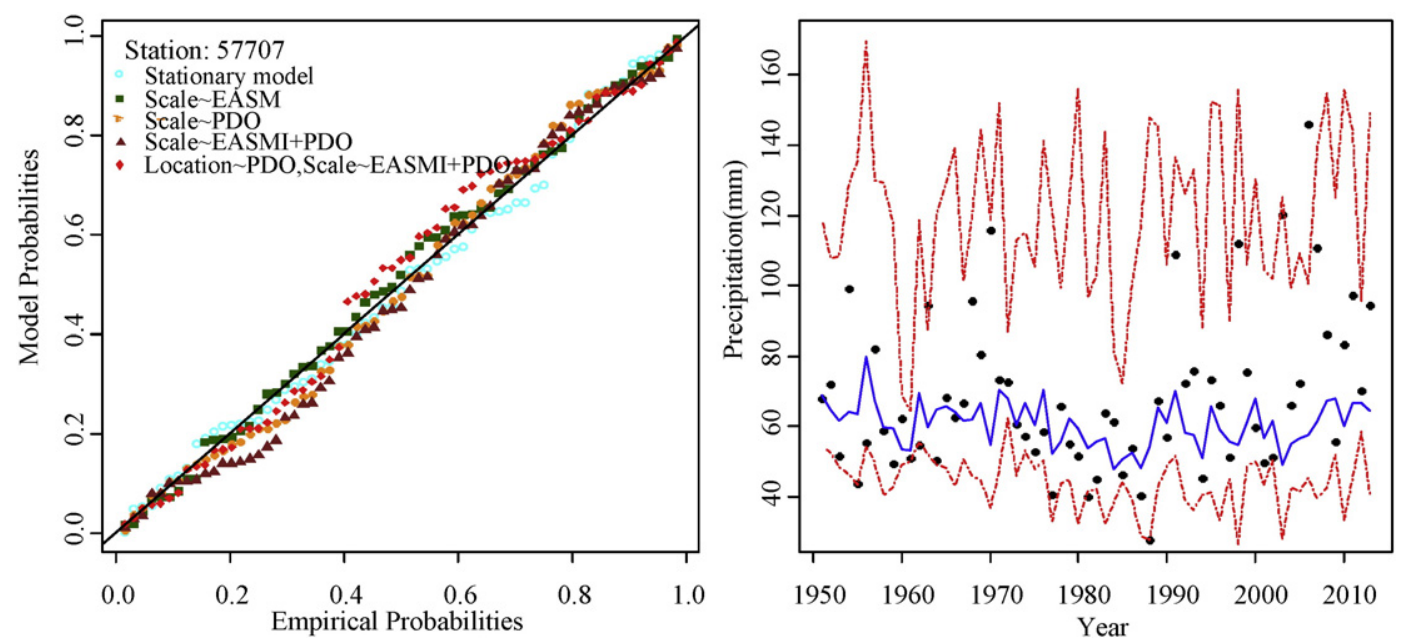

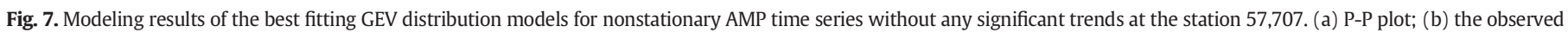
values of AMP (dots), the estimates of the median (solid lines), and the 5th and 95th percentiles (dashed lines). 

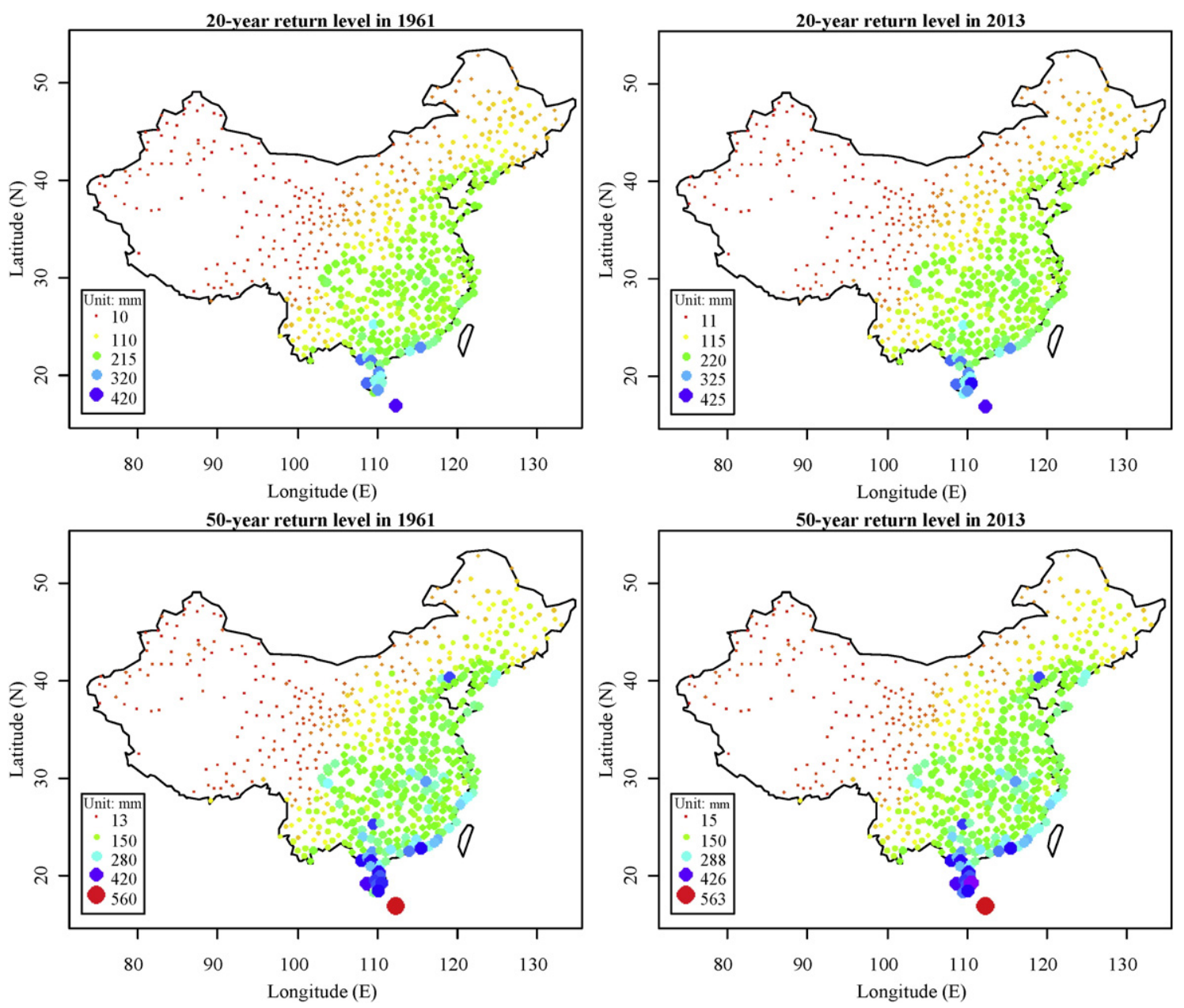

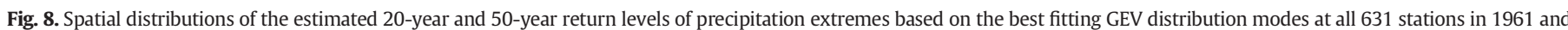
2013.

annual total precipitation, summer total precipitation, and annual precipitation extremes in China (Zhai et al., 2005; Feng et al., 2007; Qian and Qin, 2008; Xu et al., 2011; You et al., 2011; Deng et al., 2014). More specifically, a strengthening anticyclonic circulation, increasing geopotential height and rapid warming over the Eurasian continent have been considered as the reasons of climate extreme changes in China (You et al., 2011; Sun et al., 2016). In this study, nonstationary GEV distribution model performed better than the stationary one for most nonstationary AMP time series with significant positive trends. Although the positive trends have been detected in precipitation extremes in western China, the total precipitation is still at low level. Moreover, the increasing in annual maximum or total precipitation usually accompanies with the increasing of temperature (You et al., 2011); therefore, the climate in the western China is still vulnerable (Deng et al., 2014).

Previous studies also found that annual total precipitation decreased in northern China (Zhai et al., 2005; Feng et al., 2007; Qian and Qin, 2008; Xu et al., 2011; You et al., 2011; Sun et al., 2016), but we only detected negative trends in 5 nonstationary AMP time series at $5 \%$ significance level. Nonstationary GEV distribution model did not perform better than the stationary equivalents in fitting AMP time series with negative trend at two stations $(53,959$ and 57,051$)$ in central China. Another two stations $(54,429$ and 54,511) are located in northern China. As these two stations were near the largest urban agglomeration in northern China, the negative trends cannot simply attributable to climate change. The remaining station $(56,492)$ was near the Sichun Basin, where decreasing trend was also detected in annual total precipitation (Zhai et al., 2005).
The 631 stations almost cover a majority of land area in China; however, non-stationarity and trends have not been detected in most AMP time series as expected. Additionally, the correlations between nonstationary AMP time series and climate indices were not very significant either. In this study, the significance level was constrained at 5\% that was much stricter than that in previous studies (Feng et al., 2007). Thus, nonstationarity, trends, and correlations were not easily detected. Moreover, extreme precipitation was defined as the traditional annual maximum daily precipitation. As we know the terrain in China is very complex and diversified. For stations in northern and western China, AMP usually occurs during small scale convective rainfall but not large scale cyclonic rainfall. In the southern and southeastern China, extreme precipitation events usually extend over two days due to the influence of typhoons (Feng et al., 2007). Therefore, AMP could not fully represent the influence of climate change on precipitation extremes. Another more representative precipitation index would be selected for extreme value analysis under the background of climate change.

\section{Conclusions}

In this study we conducted a nonstationary extreme value analysis of precipitation extremes using a comprehensive daily precipitation dataset, from which the time series of AMP ( $\geq 50$ years) at 631 meteorological stations in China were extracted. Extreme precipitation at 48 stations showed significant non-stationarity at $5 \%$ level. Trends of AMP time series from these nonstationary stations were further tested. Among these 48 non-stationarity AMP time series, 30 AMP time series have significant trend, while the other 18 AMP time series have no significant trend. 
Nonstationary GEV distribution was then used to fit these nonstationary AMP time series. For the 30 nonstationary AMP time series with significant trends, the location parameter was varying with time. For the other 18 nonstationary AMP time series with no significant trend, we did correlation analysis with four climate indices EASMI, WPI, SOI, and PDO; then, the location and scale parameters in the GEV distribution were modeled as functions of the significantly correlated climate indices. The modeling results in this study showed that the nonstationary GEV distributions performed better than their stationary equivalents. For each station, 20-year and 50-year return levels of precipitation extremes were estimated using the best fitting GEV distribution for the year 1961 and 2013, respectively. Because only a few of AMP time series were nonstationary, the difference of 20-year and 50-year return levels of precipitation extremes between stationary and nonstationary GEV models was not very obvious over China.

\section{Acknowledgements}

This work was partly supported by the Youth Innovation Promotion Association of the Chinese Academy of Sciences (2016195), CAS Knowledge Innovation Project (KZCX2-EW-QN209), S\&T Service Network Initiative (KFJ-EW-STS-127-2), and National Natural Science Foundation of China (31570423). The authors appreciate the Climate Data Center of the National Meteorological Center of the CMA for providing the meteorological data and Dr. X.H. Wen for processing the raw data.

\section{References}

Akaike, H., 1974. A new look at the statistical model identification. IEEE Trans. Autom. Control 19 (6), 716-723.

Barnston, A., Livezey, R., 1987. Classification seasonality and persistence of low-frequency atmospheric circulation patterns. Mon. Weather Rev. 115, 1083-1126.

Boccolari, M., Malmusi, S., 2013. Changes in temperature and precipitation extremes observed in Modena, Italy. Atmos. Res. 122, 16-31.

Cheng, L.L., AghaKouchak, A., Gilleland, E., Katz, R.W., 2014. Non-stationary extreme value analysis in a changing climate. Clim. Chang. 127, 353-369.

Cino, T.A., de Guzman, R.G., Hilario, F.D., Wilson, D.M., 2014. Long-term trends and extremes in observed daily precipitation and near surface air temperature in the Philippines for the period 1951-2010. Atmos. Res. 145-146, 12-26.

Coles, S., 2001. An Introduction to Statistical Modeling of Extreme Values. Springer.

Deng, H., Chen, Y., Shi, X., Li, W., Wang, H., Zhang, S., Fang, G., 2014. Dynamics of temperature and precipitation extremes and their spatial variation in the arid region of northwest China. Atmos. Res. 138, 346-355.

Ding, Y.H., Chan, J.C.L., 2005. The East Asian summer monsoon: an overview. Meteorog. Atmos. Phys. 89, 117-142

Du, H., Xia, J., Zeng, S., She, D., Liu, J., 2014. Variations and statistical probability characteristic analysis of extreme precipitation events under climate change in Haihe Rive Basin, China. Hydrol. Process. 28, 913-925.

Feng, S., Nadarajah, S., Hu, Q., 2007. Modeling annual extreme precipitation in China using the generalized extreme value distribution. J. Meteor. Soc. Japan 85, 599-613.

Fischer, T., Gemmer, M., Liu, L., Su, B., 2012a. Change-points in climate extremes in the Zhujiang River Basin, South China, 1961-2007. Clim. Chang. 110, 783-799.

Fischer, T., Su, B.D., Luo, Y., Scholten, T., 2012b. Probability distribution of precipitation extremes for weather-index based insurance in the Zhujiang River Basin, South China. J. Hydrol. Meteor. 13, 1023-1037.

Fu, G.B., Viney, N.R., Charles, S.P., Liu, J., 2010. Long-term temporal variation of extreme rainfall events in Australia: 1910-2006. J. Hydrometeorol. 11 (4), 950-965.

Goswami, B.N., Venugopal, V., Sengupta, D., Madhusoodanan, M., Xavier, P.K., 2006. Increasing trend of extreme rain events over India in a warming environment. Science 314 (5804), 1442-1445.

IPCC, 2007. Climate Change 2007: The Physical Science Basis. Contribution of Working Group I to the Fourth Assessment Report of the Intergovernmental Panel on Climate Change. Cambridge University, Cambridge, UK.

Jenkinson, A.F., 1955. The frequency distribution of the annual maximum (or minimum) values of meteorological elements. Quart. J. R. Meteor. Soc. 81, 158-171.

Katz, R.W., 2013. Statistical methods for nonstationary extremes. In: AghaKouchak, A Easterling, D., Hsu, K., Schubert, S., Sorooshian, S. (Eds.), Extremes in a Changing Climate. Springer, pp. 15-38.

Katz, R.W., Parlange, M.B., Naveau, P., 2002. Statistics of extremes in hydrology. Adv. Water Res. 25, 1287-1304

Kendall, M.G., 1938. A new measure of rank correlation. Biometrika 30, 81-93.

Kiem, A.S., Franks, S.W., Kuczera, G., 2003. Multi-decadal variability of flood risk. Geophys. Res. Lett. 30 (2), GL015992.

Klein Tank, A., Können, G., 2003. Trends in indices of daily temperature and precipitation extremes in Europe, 1946-99. J. Clim. 16 (22), 3665-3680.

Kwiatkowski, D., Phillips, P.C.B., Schmidt, P., Shin, Y., 1992. Testing the null of stationarity against the alternative of a unit root: how sure are we that economic time series have a unit root? J. Econ. 54, 159-178.
Li, J.P., Zeng, Q.C., 2003. A new monsoon index and the geographical distribution of the global monsoons. Adv. Atmos. Sci. 20, 299-302.

Li, J.P., Zeng, Q.C., 2005. A new monsoon index, its interannual variability and relation with monsoon precipitation. Clim. Environ. Res. 10 (3), 351-365.

Li, Z., Brissette, F., Chen, J., 2013. Finding the most appropriate precipitation probability distribution for stochastic weather generation and hydrological modelling in Nordic watersheds. Hydrol. Process. 27 (25), 3718-3729.

Limsakul, A., Singhruck, P., 2016. Long-term trends and variability of total and extreme precipitation in Thailand. Atmos. Res. 169, 301-317.

Lin, L., Lu, R., 2009. The ENSO's effect on eastern China rainfall in the following early summer. Adv. Atmos. Sci. 26 (2), 333-342.

Mann, H.B., 1945. Nonparametric test against trend. Econometrica 13, 245-259.

Mantua, N.J., Hare, S.R., 2002. The Pacific decadal oscillation. J. Oceanogr. 58, 35-44.

Mika, J., 2013. Changes in weather and climate extremes: phenomenology and empirical approaches. Clim. Chang. 121, 15-26.

Monier, E., Gao, X., 2015. Climate change impacts on extreme events in the United States: an uncertainty analysis. Clim. Chang. 131 (1), 67-81.

Olsen, J.R., Lambert, J.H., Haimes, Y.Y., 1998. Risk of extreme events under nonstationary conditions. Risk Anal. 18 (4), 497-510.

Olsen, J.R., Stedinger, J.R., Matalas, N.C., Stakhiv, E.Z., 1999. Climate variability and flood frequency estimation for the upper Mississippi and lower Missouri rivers. J. Am. Water Resour. Assoc. 35 (6), 1509-1523.

Qian, W., Lin, X., 2005. Regional trends in recent temperature indices in China. Meteorog. Atmos. Phys. 90, 193-207.

Qian, W.H., Qin, A., 2008. Precipitation division and climate shift in China from 1960 to 2000. Theor. Appl. Climatol. 93, 1-17.

R Development Core Team, 2014. R: A Language and Environment for Statistical Computing. Version 3.0.3.

Radinović, D., Ćurić, M., 2009. Deficit and surplus of precipitation as a continuous function of time. Theor. Appl. Climatol. 98, 197-200.

Radinović, D., Ćurić, M., 2013. Measuring system of adverse weather phenomena. Dis. Adv. 6, 19-23.

Radinović, D., Ćurić, M., 2014. Measuring scales for daily temperature extremes, precipitation and wind velocity. Meteorol. Appl. 21, 46-465.

Salas, J.D., Obeysekera, J., 2014. Revisiting the concepts of return period and risk for nonstationary hydrologic extreme events. J. Hydrol. Eng. 19, 554-568.

Singh, V., Goyal, M.K., 2016. Analysis and trends of precipitation lapse rate and extreme indices over north Sikkim eastern Himalayas under CMIP5ESM-2M RCPs experiments. Atmos. Res. 167, 34-60.

Song, X., Song, S., Sun, W., Mu, X., Li, J., Li, Y., 2015. Recent changes in extreme precipitation and drought over the Songhua River Basin, China, during 1960-2013. Atmos. Res. 157, 137-152.

Soukissian, T.H., Tsalis, C., 2015. The effect of the generalized extreme value distribution parameter estimation methods in extreme wind speed prediction. Nat. Hazards 78, $1777-1809$

Su, B.D., Jiang, T., Jin, W.B., 2006. Recent trends in observed temperature and precipitation extremes in the Yangtze River basin, China. Theor. Appl. Climatol. 83,139-151.

Sui, C., Chung, P., Li, T., 2007. Interannual and interdecadal variability of the summertime western North Pacific subtropical high. Geophys. Res. Lett. 34, L11701.

Sun, W., Mu, X., Song, X., Wu, D., Cheng, A., Qiu, B., 2016. Changes in extreme temperature and precipitation events in the Loess Plateau (China) during 1960-2013 under global warming. Atmos. Res. 68, 33-48.

Tanaka, M., 1997. Interannual and interdecadal variation of the Western North Pacific monsoon and the East Asian Baiu rainfall and their relationship to enso cycle. J. Meteor. Soc. Japan 75, 1109-1123.

Trenberth, KE 1997. The definition of El Niño. Bull. Am. Meteorol. Soc. 78, 2771-2777.

Villafuerte II, M.Q., Matsumoto, J., Akasaka, I., Takahashi, H.G., Kubota, H., Cinco, T.A., 2014. Long-term trends and variability of rainfall extremes in the Philippines. Atmos. Res. 137, $1-13$.

Villarini, G., Serinaldi, F., Smith, J.A., Krajewski, W.F., 2009. On the stationarity of annual flood peaks in the continental United States during the 20th century. Water Resour. Res. 45 (8), W08417.

Villarini, G., Smith, J.A., Napolitano, F., 2010. Nonstationary modeling of a long record of rainfall and temperature over Rome. Adv. Water Res. 33, 1256-1267.

Wang, B., Wu, F., Fu, X., 2000. Pacific-East Asian teleconnection: how does ENSO affect East Asian climate? J. Clim. 13, 1517-1536.

Wigley, T.M.L., 2009. The effect of changing climate on the frequency of absolute extreme events. Clim. Chang. 97, 67-76.

Xu, X., Du, Y., Tang, J., Wang, Y., 2011. Variations of temperature and precipitation extremes in recent two decades over China. Atmos. Res. 101, 143-154

You, Q., Kang, S., Aguilar, E., Pepin, N., Flügel, W.A., Yan, Y., Xu, Y., Zhang, Y., Huang, J., 2011. Changes in daily climate extremes in China and their connection to the large scale atmospheric circulation during 1961-2003. Clim. Dyn. 36 (11), 2399-2417.

Zhai, P., Zhang, X.B., Wan, H., Pan, X., 2005. Trends in total precipitation and frequency of daily precipitation extremes over China. J. Clim. 18, 1097-1109.

Zhang, D.D., Yan, D.H., Wang, Y.C., Lu, F., Liu, S.H., 2015. GAMLSS-based nonstationary modeling of extreme precipitation in Beijing-Tianjin-Hebei region of China. Nat. Hazards 77, 1037-1053.

Zhao, P., Zhou, Z.J., 2009. An East Asian subtropical summer monsoon index and its relationship to summer rainfall in China. Acta Meteorol. Sin. 23, 18-28.

Zhou, X.Y., Ding, Y.H., Wang, P.X., 2008. Moisture transport in Asian summer monsoon region and its relationship with summer precipitation in China. Acta Meteorol. Sin. 66, 59-70. 